\title{
EL ASUNTO DE LAS PLANTAS DE CELULOSA SOBRE EL RÍO URUGUAY
}

\author{
THE PULP MILLS OVER THE RIVER URUGUAY CASE
}

\author{
COMENTARIO DE LA SENTENCIA DE LA CORTE INTERNACIONAL DE JUSTICIA, \\ DE FECHA 20 DE ABRIL DE 2010
}

\section{Sebastián López Escarcena*}

\begin{abstract}
RESUMEN: La construcción de dos papeleras en la orilla oriental del río Uruguay provocó un conflicto interestatal que terminó con una sentencia de la Corte Internacional de Justicia que, además de solucionar el problema entre las partes en disputa, desarrolla importantes principios del Derecho Internacional ambiental, como la prevención, la precaución y el estudio del impacto ambiental para proyectos de inversión. Lejos de ser un fallo irrelevante en la evolución de esta parte del Derecho Internacional, el asunto de las plantas de celulosa sobre el río Uruguay pertenece al puñado de decisiones de la Corte que se refieren con cierto detalle a los principios jurídicos en los cuales se funda la protección internacional del medio ambiente.
\end{abstract}

Palabras clave: Corte Internacional de Justicia; prevención; precaución; estudio de impacto ambiental.

ABSTRACT: The construction of two plants of cellulose in the Eastern bank of the River Uruguay provoked an inter-state conflict that ended up with a sentence of the International Court of Justice that, besides settling the issue between the parties in dispute, develops important principles of international environmental law, like prevention, precaution and environmental impact assessment for investment projects. Far from being an irrelevant judgment in the evolution of this part of international law, the Pulp Mills in the River Uruguay case belongs to the handful of the court's decisions which refer with certain detail to the legal principles on which the international protection of the environment is based.

Key words: International Court of Justice; prevention; precaution; environmental impact assessment.

\section{INTRODUCCIÓN ${ }^{* *}$}

El 20 de abril de 2010, la Corte Internacional de Justicia (“CIJ”) comunicó la sentencia que puso fin al conflicto entre Argentina y Uruguay, proveniente de la construcción de dos papeleras en la orilla derecha del río que constituye el límite natural entre ambos países. Si bien esta disputa se remonta al año 2003, solo en el 2006 Argentina presentó la

\footnotetext{
Profesor de Derecho Internacional e investigador de la Facultad de Derecho de la Pontificia Universidad Católica de Chile. PhD (Edinburgh), LLM (Leiden), Abogado y Licenciado en Derecho (Católica de Chile). Correo electrónico: rlopeze@uc.cl

** Trabajo presentado en Concepción el 28 de septiembre de 2012, en los Coloquios de Derecho Internacional organizados por Facultad de Ciencias Jurídicas y Sociales de la Universidad de Concepción.
} 
solicitud respectiva. La CIJ tuvo que fallar negativamente dos peticiones de medidas provisionales, una argentina en el 2006 y otra uruguaya en el 2007, antes de resolver el conflicto de manera definitiva el 2010. Esta sentencia fue recibida con satisfacción por ambas partes, quienes se comprometieron a respetar y ejecutar el fallo de la CIJ. En Argentina, el gobierno de turno estimó que esta decisión les daba la razón, al menos parcialmente. Fueron de la misma opinión las autoridades uruguayas de entonces.

¿Qué fue lo que realmente pasó en este caso, y qué fue lo que falló la CIJ en concreto? El presente comentario pretende responder estas preguntas, destacando la importancia que tiene la sentencia de la CIJ en el asunto de las plantas sobre el río Uruguay, desde un punto de vista jurisprudencial -esto es, del conjunto de principios que emanan de las decisiones judiciales-, como medio auxiliar en la determinación de las reglas de Derecho. Principios que, en el caso de las sentencias de la CIJ Internacional de Justicia, desempeñan un rol central en el desarrollo del Derecho Internacional.

\section{EL CONFLICTO}

La frontera entre Argentina y Uruguay se estableció en el "Tratado de límites del río Uruguay", celebrado entre ambos Estados en $1961^{1}$. En cumplimiento de dicho acuerdo ${ }^{2}$, Argentina y Uruguay celebraron un nuevo tratado en 1975 denominado "Estatuto del río Uruguay" ("Estatuto de 1975”), por el que se creó la Comisión Administradora del Río Uruguay ("CARU") como una organización internacional destinada a institucionalizar un sistema global de administración del río, en el tramo compartido por ambos países ${ }^{3}$. Este último tratado contempla diversas obligaciones cuyo fin es el óptimo y racional aprovechamiento común del río Uruguay. Los artículos 7 a 12 del Estatuto de 1975 establecen un mecanismo de consulta y notificación a la CARU y entre las partes, para cualquier trabajo que pueda afectar la navegación, el régimen del río o la calidad de sus aguas. Fue en el contexto de este marco regulatorio que, a partir del 2005, se proyectó construir dos papeleras para producir pasta de celulosa en la orilla este del río. La suma de los montos involucrados en ambas papeleras constituyó, en su momento, la mayor inversión proyectada en la historia de Uruguay ${ }^{4}$.

La primera de las papeleras pertenecía a "Celulosas de M’Bopicuá S.A." (“CMB”), de propiedad de la "Empresa Nacional de Celulosas de España" ("ENCE”). Iba a ser construida en el departamento uruguayo de Río Negro, muy cerca de la ciudad de Fray Bentos y del puente internacional "Libertador General San Martín". La compañía a cargo del proyecto presentó un estudio de impacto ambiental ("EIA") del plan a las autoridades uruguayas en el 2002, e informó al Presidente de la CARU de este hecho. A petición del Presidente de la CARU, el 2003 el Estado uruguayo envió una copia del EIA a esa entidad. Uruguay emitió el 9 de octubre de ese año una autorización ambiental previa para la cons-

\footnotetext{
1 Vigente desde ese año.

2 Específicamente, de su artículo 7.

3 El Estatuto de 1975 entró en vigencia al año siguiente. Tanto el tratado de límites de 1961, como el Estatuto de 1975, están disponibles en http://www.caru.org.uy/publicaciones/Documentos-y-antecedentesPublicacion-1998.pdf [fecha de consulta: 1 de octubre de 2012].

4 Payne (2010a) p. 318; Juste Ruiz y Bou Franch (2011) p. 4; y Payne (2011) p. 96.
} 
trucción de la planta CMB-ENCE, sin que las partes se pusieran de acuerdo en la implementación del mecanismo de consulta y notificación previsto por el Estatuto de 1975. El 28 de noviembre del 2005, el gobierno uruguayo otorgó un permiso para efectuar los trabajos preparatorios de limpieza de los terrenos en que se construiría la referida planta. Estas noticias no fueron bien recibidas en el departamento argentino de Gualeguaychú, provincia de Entre Ríos, particularmente en la ciudad del mismo nombre. Se produjo entonces una tensión internacional entre los dos países, que acabaría transformándose en controversia no mucho después. El 28 de marzo de 2006, la empresa a cargo del proyecto decidió suspender la construcción de la planta, y el 21 de septiembre de ese año anunció su intención de no continuar con el proyecto 5 .

La segunda papelera proyectada se llama "Orion" y pertenecía originalmente a "Botnia S.A.” y "Botnia Fray Bentos S.A.” (“Botnia”), dos empresas creadas por la compañía finlandesa "Oy Metsä-Botnia AB". Como la planta CMB-ENCE, esta segunda papelera fue construida cerca de Fray Bentos, a pocos kilómetros del sitio planeado para la primera. Botnia presentó un EIA a las autoridades uruguayas el 2004, quienes al año siguiente le otorgaron una autorización ambiental previa al proyecto, y un permiso para realizar los trabajos preparatorios de limpieza de los terrenos donde se construiría la planta. Informada que la Corporación Financiera Internacional ("CFI") iba a contribuir al proyecto de Botnia, Argentina expresó su preocupación a esta organización internacional el 2005. Si bien la CFI decidió finalmente contribuir con la planta Orion, lo hizo previa solicitud de varios informes técnicos sobre el proyecto a una consultora especializada en asuntos ambientales e industriales llamada EcoMetrix, no solo antes de su entrada en funcionamiento, sino también una vez en servicio. Ese mismo año, Uruguay autorizó la construcción de un puerto adyacente a Orion, lo cual fue comunicado a la CARU. El 2006, Uruguay otorgó a Botnia una autorización para extraer y usar aguas del río para objetivos industriales, lo que nuevamente fue informado a la CARU. Un año después, Uruguay autorizó el funcionamiento de Orion, la que entró en servicios al día siguiente. El Estado uruguayo autorizó la construcción de un terminal portuario el 2007, lo que fue comunicado a la CARU. A fines del 2009, Botnia transfirió sus intereses en Orion a "UPM-Kymmene Oyj” (“UPM"), otra compañía finlandesa ${ }^{6}$.

A raíz de las dificultades entre Argentina y Uruguay, derivadas de este proyecto y el de CMB-ENCE, ambos Estados acordaron crear el 2005 un Grupo Técnico de Alto Nivel (“GTAN"), facultado para resolver las disputas relativas a las plantas. El GTAN se reunió durante ese año y el siguiente, hasta que Uruguay dio por fracasadas las negociaciones, lo que provocó una declaración similar de Argentina. El 4 de mayo de 2006, Argentina presentó una solicitud ante la CIJ en virtud del artículo 60 del Estatuto de 1975, iniciando un proceso que terminó con la sentencia del tribunal casi cuatro años después. Entre ambas fechas, un tribunal arbitral ad hoc establecido conforme al sistema de solución de controversias del Mercado Común del Sur ("Mercosur") falló favorablemente una petición uruguaya

\footnotetext{
5 Ver, en general, plantas de celulosa sobre el río Uruguay (2010): CIJ (sentencia) párrafos 28-36. CMB-ENCE desistió de su papelera por la presión pública a la que fue sometida en y por Argentina. PAYNe (2010b) p. 2; Juste Ruiz y Bou Franch (2011) p. 4; y Kazhdan (2011) p. 543.

6 Ver, en general, plantas de celulosa sobre el río Uruguay (2010): CIJ (sentencia) Párrafos 37-46. Más detalles de la historia del conflicto en KazhDan (2011) pp. 541-4.
} 
del 2006, provocada por el bloqueo de carreteras argentinas y del puente internacional que une ambos países, por individuos y grupos ambientales que protestaban por la construcción de las plantas de celulosa, el cual afectaba la libre circulación de bienes, servicios y factores productivos que asegura el derecho del Mercosur ${ }^{7}$. Por su parte, y en el mismo período, la CIJ no acogió ninguna de las medidas provisionales solicitadas por cada parte en conflicto. La de Argentina buscaba que Uruguay suspendiera toda autorización relativa a las papeleras, así como la construcción de estas, mientras no se hubiere resuelto la controversia por sentencia de la $\mathrm{CIJ}^{8}$. La de Uruguay, en cambio, buscaba que Argentina adoptara las medidas necesarias para prevenir o poner término a la interrupción del tránsito entre los dos países provocada por los nuevos bloqueos en las carreteras argentinas y el puente internacional, que el laudo del tribunal ad hoc del Mercosur no pudo impedir?'.

\section{LA SENTENCIA}

Argentina alegó que Uruguay había incurrido en responsabilidad internacional al no cumplir las obligaciones contraídas en el Estatuto de 1975 y otras normas internacionales. Dentro de estas obligaciones, el Estado demandante mencionó las siguientes: adoptar todas las medidas necesarias para el óptimo y racional aprovechamiento del río Uruguay; notificar de manera previa a la CARU y a la otra parte del tratado; seguir los procedimientos de consulta que establece dicho acuerdo internacional; adoptar todas las medidas necesarias para preservar el medio acuático y prevenir la contaminación, y para proteger la biodiversidad y la pesca, incluyendo la preparación de un completo y objetivo EIA; y cooperar en la prevención de la contaminación y la protección de la biodiversidad y la pesca. Argentina solicitó a la CIJ que Uruguay cese en su conducta ilícita y reanude el cumplimiento de sus obligaciones internacionales, ofrezca garantías de no repetición, y repare íntegramente el perjuicio causado por su violación de los deberes antes señalados, a través de la restitución e indemnización ${ }^{10}$. Uruguay, por su parte, solicitó a la CIJ que rechace las reclamaciones argentinas, y declare su derecho a continuar operando las papeleras conforme a las disposiciones del Estatuto de 1975. De lo contrario, agregó el Estado uruguayo, el daño provocado a su economía sería sustancial -en términos de pérdida de trabajos e ingresos- y desproporcionadamente oneroso en comparación a su supuesto incumplimiento del Estatuto de 1975. En caso que la CIJ concluyera que Uruguay había violado las obligaciones procesales

\footnotetext{
7 La responsabilidad internacional de Argentina se debió a su falta de debida diligencia en la prevención de los bloqueos y el restablecimiento del orden público. Ver, en general, PAvón Piscitello y Andrés (2007) pp. 172-80. Hubo también intentos de solucionar el conflicto en tribunales argentinos y uruguayos; por medio de reclamaciones ante la CFI, y de los buenos oficios de la Organización de Estados Americanos y del Rey de España; e incluso a través de la Comisión Interamericana de Derechos Humanos. Ver Pavón Piscitello y AnDrés (2007) pp. 180-2; Payne (2010a) pp. 318-20; Payne (2010b) p. 2; Anglés Hernández (2011) pp. 82-3; y Juste Ruíz Y Bou Franch (2011) p. 4-5.

8 Ver, en general, plantas de celulosa sobre el río Uruguay (2006): CIJ (medidas provisionales).

9 Ver, en general, plantas de celulosa sobre el río Uruguay (2007): CIJ (medidas provisionales).

10 Ver plantas de celulosa sobre el río Uruguay (2010): CIJ (sentencia) párrafos 1 y 22-4.
} 
que establece dicho tratado, el Estado demandado propuso que la sentencia constituya una forma de satisfacción adecuada ${ }^{11}$.

Esto último es justamente lo que la CIJ falló en el asunto de las plantas de celulosa sobre el río Uruguay, descartando la alegación argentina de incumplimiento de obligaciones sustantivas, así como su solicitud de cesación, no repetición y reparación ${ }^{12}$. Cabe destacar que el tribunal restringió su análisis al Estatuto de 1975 y las normas de Derecho Internacional general necesarias para su interpretación y aplicación, descartando los otros tratados internacionales que Argentina alegaba como incorporados por referencia al estatuto, entre las cuales se encontraban la "Convención sobre el comercio internacional de especies amenazadas de fauna y flora silvestres", de 1973; la "Convención relativa a los humedales de importancia internacional” o Convención de Ramsar, de 1971; el "Convenio de Naciones Unidas sobre diversidad biológica”, de 1992; y el "Convenio sobre los contaminantes orgánicos persistentes" o Convenio de Estocolmo, de $2001^{13}$.

La CIJ identificó dos obligaciones procesales convencionales violadas por Uruguay: el deber de comunicar a la CARU, y el de notificar a Argentina a través de la CARU la realización de cualquier obra de entidad suficiente para afectar la navegación, el régimen del río o la calidad de sus aguas ${ }^{14}$. Respecto de las obligaciones sustantivas del Estatuto de 1975, el tribunal rechazó cada uno de los supuestos incumplimientos alegados por la parte demandante, referidos a los deberes de contribuir al óptimo y racional aprovechamiento del río ${ }^{15}$; adoptar las medidas necesarias para asegurar que el manejo del suelo y de los bosques, la utilización de las aguas subterráneas y la de los afluentes del río no causen una alteración que perjudique sensiblemente su régimen o la calidad de sus aguas ${ }^{16}$; coordinar, por intermedio de la CARU, las medidas adecuadas para evitar la alteración del equilibrio ecológico del río ${ }^{17}$; proteger y preservar el medio acuático, y prevenir su contaminación ${ }^{18}$. Finalmente, la CIJ recordó a las partes litigantes que el Estatuto de 1975 las obliga a cooperar entre sí a fin de asegurar el logro de su objeto y propósito; lo que en este caso se traduce en la

\footnotetext{
11 Ver plantas de celulosa sobre el río Uruguay (2010): CIJ (sentencia) Párrafos 22-4. Según Dire Tladi, Uruguay anticipaba que la CIJ iba a fallar en su contra respecto de estas obligaciones, lo que explicaría su solicitud. TLADI (2012) p. 5.

12 Ver plantas de celulosa sobre el río Uruguay (2010): CIJ (sentencia) párrafos 267, 269, 275-6, 278 y 282.

13 Ver plantas de celulosa sobre el río Uruguay (2010): CIJ (sentencia) Párrafos 53 y 56-63. Con esto, el tribunal dejó fuera de su jurisdicción las alegaciones argentinas sobre contaminación del aire, acústica y visual. Únicamente la potencial contaminación del aire, que pudiera afectar la calidad de las aguas del río Uruguay, quedó dentro de la competencia de la CIJ. Ver plantas de celulosa sobre el río Uruguay (2010): CIJ (sentencia). Párrafos 52 y 264.

14 Artículo 7 del Estatuto de 1975. Ver plantas de celulosa sobre el río Uruguay (2010): CIJ (sentencia) párrafos 67-158. Ver, también, Anton (2010) pp. 216-7; Merkouris (2010) pp. 1-2 y 5-7; y Juste Ruiz y Bou Franch (2011) pp. 18-20. Las obligaciones de comunicación y notificación del Estatuto de 1975 no son otra cosa que la expresión convencional del deber de cooperación transfronteriza en casos de riesgo ambiental que establece el derecho internacional general. Ver en general Birnie, Boyle y Redgwell (2009) pp. 175-84.

15 Artículo 1 del Estatuto de 1975.

16 Artículo 35 del Estatuto de 1975.

17 Artículo 36 del Estatuto de 1975.

18 Artículo 41 del Estatuto de 1975.

Ver plantas de celulosa sobre el río Uruguay (2010): CIJ (sentencia) párrafos 159-266. Ver, también, Anton (2010) pp. 217-22; Merkouris (2010) pp. 8-11; Juste Ruiz y Bou Franch (2011) pp. 20-7; y Payne (2011) pp. 97-8.
} 
exigencia de un monitoreo continuo y conjunto del funcionamiento de la papelera restante a través de la CARU ${ }^{19}$.

Para Argentina y Uruguay, eso fue el quid de la sentencia. Sin embargo, desde el punto de vista de la dogmática jurídica, la importancia de este caso radica en el desarrollo jurisprudencial de ciertos conceptos que le aseguran un lugar destacado en la historia del Derecho Internacional ambiental, particularmente en relación a los principios de prevención y precaución, y la obligación de realizar un EIA ${ }^{20}$.

\section{PREVENCIÓN Y PRECAUCIÓN}

Si bien la CIJ centró su análisis en la interpretación y aplicación del Estatuto de 1975, al hacerlo tuvo en cuenta el Derecho Internacional general, pronunciándose sobre el estatus consuetudinario de varias de las reglas en cuestión ${ }^{21}$. Dentro de estas, el tribunal tuvo la oportunidad de referirse a aquellas que consagran los principios de prevención y precaución en el Derecho Internacional ambiental consuetudinario. La CIJ explica estos principios desde la noción de desarrollo sustentable, tal como fuera explicitado en el caso Gabčikovo-Nagymaros de 1997, equilibrando la conservación del ambiente fluvial y los derechos económicos de los Estados ribereños, a través de la cooperación entre las partes litigantes ${ }^{22}$. Más que una norma, la CIJ considera al desarrollo sustentable como un objetivo ${ }^{23}$. Conforme lo entiende el tribunal, el principio de prevención tiene su origen en la obligación de debida diligencia que se requiere de un Estado respecto de su territorio, en los términos previstos en el caso del estrecho de Corfú de 1949 y la opinión consultiva sobre la legalidad de la amenaza o el uso de armas nucleares de $1996^{24}$. Es desde esta perspectiva que la CIJ interpreta el deber de consulta a la CARU establecida por el Estatuto de 1975, a fin que esta pueda realizar una evaluación preliminar de aquellos proyectos que puedan causar daño a la otra parte ${ }^{25}$. Dicha comunica-

\footnotetext{
19 Ver plantas de celulosa sobre el río Uruguay (2010): CIJ (sentencia) párrafos 184-7, 266 \& 281. Sobre el principio de cooperación en el derecho internacional ambiental, ver BoyLE (2007) pp. 378-80.

20 Algunos autores han destacado el aporte de esta sentencia en materia probatoria para procedimientos ante la CIJ, debido a que el tribunal criticó expresamente la presentación de peritos como consejeros de las partes, lo que privó a estas y a la CIJ de la posibilidad de hacerles preguntas en su calidad de tales. Ver plantas de celulosa sobre el río Uruguay (2010): CIJ (sentencia) párrafo 167. Ver Anton (2010) pp. 222-3; Merkouris (2010) p. 9; Payne (2010a) pp. 322-3; Payne (2010b) p. 6; Juste Ruiz y Bou Franch (2011) pp. 11-2; y Payne (2011) p. 99.

21 Anton (2010) p. 214.

22 Plantas de celulosa sobre el río Uruguay (2010): CIJ (sentencia) párrafo 75, párrafos 76-7, 175 y 177. La cita de la CIJ se refiere a Gabčikovo-Nagymaros (1997): CIJ (sentencia) párrafos 140-1.

23 Thadi (2012) p. 12. Sobre el concepto de desarrollo sustentable en el derecho internacional ambiental, ver en general Birnie, Boyle y Redgwell (2009) pp. 53-8 y 115-27.

24 Ver plantas de celulosa sobre el río Uruguay (2010): CIJ (sentencia) párrafo 101. Las referencias de la CIJ son a estrecho de Corfú (1949): CIJ (sentencia) ICJ Reports 1949 p. 22; y a legalidad de la amenaza o el uso de armas nucleares... (1996): CIJ (opinión consultiva) párrafo 29. Respecto a la debida diligencia y el principio de prevención en el derecho internacional ambiental, ver Birnie, Boyle y Redgwell (2009) pp. 147-50. Sobre este principio y su naturaleza jurídica, ver en general id. pp. 143-52

25 Ver plantas de celulosa sobre el río Uruguay (2010): CIJ (sentencia) párrafos 102, 104-5 y 111.
} 
ción se debe realizar tan pronto el Estado en cuestión tenga en su poder un plan suficientemente desarrollado del proyecto correspondiente ${ }^{26}$.

Aunque el tribunal no lo menciona expresamente, el mismo principio sirve para interpretar el deber de notificación a la otra parte que contempla dicho tratado, dado que ambas obligaciones son manifestaciones de la cooperación que se deben Argentina y Uruguay conforme al Estatuto de $1975^{27}$. Según lo señalado por la CIJ, la notificación debe comprender un completo EIA del proyecto respectivo ${ }^{28}$. La diferencia entre ambas obligaciones radicaría en que mientras la CARU tendría que decidir si el proyecto comunicado cae dentro del procedimiento de cooperación establecido por el tratado, la parte notificada tendría que pronunciarse sobre el potencial impacto de dicho proyecto en el río y en la calidad de sus aguas ${ }^{29}$. Para la CIJ, tanto la obligación de consulta como la de notificación deben cumplirse antes de que el Estado correspondiente otorgue las autorizaciones ambientales pertinentes ${ }^{30}$. Sin perjuicio de lo anterior, el tribunal considera que no es necesario suspender el proyecto entre la finalización del procedimiento de consulta y notificación previsto por el Estatuto de 1975, y su propia sentencia. La razón que da la CIJ es que su jurisdicción se reduce a la solución de conflictos sobre la interpretación y aplicación del tratado, por lo que no contemplaría un pronunciamiento sobre la conveniencia o inconveniencia del proyecto restante, en la forma de una aprobación o rechazo del mismo ${ }^{31}$.

En cuanto al principio de precaución, la CIJ no lo menciona como tal. El tribunal habla de una aproximación precautoria, y la analiza desde una perspectiva procesal ${ }^{32}$. Es la primera vez que la CIJ se refiere a este principio en uno de sus fallos. Antes solo lo habían hecho algunos de sus jueces, en opiniones concurrentes o disidentes ${ }^{33}$. En este caso, la CIJ señala que la precaución puede ser relevante para la interpretación y aplicación de las disposiciones del Estatuto de 1975, pero no invierte la carga de la prueba, como alegaba Argentina $^{34}$. La doctrina entiende que la aproximación precautoria conlleva una obligación de controlar los riesgos ambientales previsibles, a través de la debida diligencia en el actuar del Estado correspondiente. La pregunta es cuándo surge esta obligación de control diligente. Esta es una determinación que debe hacerse caso a caso, teniendo en cuenta la magnitud y probabilidad del daño respectivo, siempre que tenga una base científica. En otras palabras, se requieren motivos razonables de preocupación: meras conjeturas no servirían de funda-

\footnotetext{
26 Ver plantas de celulosa sobre el río Uruguay (2010): CIJ (sentencia) Párrafo 105.

27 Ver plantas de celulosa sobre el río Uruguay (2010): CIJ (sentencia) Párrafos 102 y 113.

28 Ver plantas de celulosa sobre el río Uruguay (2010): CIJ (sentencia) Párrafos 116 y 119.

29 Ver plantas de celulosa sobre el río Uruguay (2010): CIJ (sentencia) Párrafo 104.

30 Ver plantas de celulosa sobre el río Uruguay (2010): CIJ (sentencia) Párrafos 105, 111 y 120.

31 Ver plantas de celulosa sobre el río Uruguay (2010): CIJ (sentencia) Párrafos 151 y 154-7.

32 En relación a la distinción entre principio y aproximación precautoria, ver BIRNIE, Boyle y RedGWELL (2009) pp. 154-6.

33 KAZHDAN (2011) p. 539.

34 Ver plantas de celulosa sobre el río Uruguay (2010): CIJ (sentencia) Párrafo 164. Ver, también, Merkouris (2010) p. 8; Payne (2010b) pp. 5-6; Kazhdan (2011) pp. 544-6; Payne (2011) pp. 97 y 101; y Tladi (2012) p. 7. La negativa de la CIJ a invertir la carga de la prueba se condice con la jurisprudencia internacional mayoritaria al respecto. Birnie, Boyle y Redgwell (2009) pp. 158-9. Cf. Juste Ruiz y Bou Franch (2011) pp. 15-6.
} 
mento suficiente ${ }^{35}$. La CIJ no recoge todo este desarrollo doctrinal en su fallo, y únicamente señala que la aproximación precautoria no tiene el efecto querido por Argentina respecto al onus probandi $i^{36}$.

\section{EL ESTUDIO DE IMPACTO AMBIENTAL}

Normalmente se entiende en doctrina que el principio de prevención consiste en una obligación continua de minimizar, en la medida de lo posible, el riesgo de daño ambiental significativo. La prevención estaría, por tanto, vinculada al principio de precaución y al concepto de desarrollo sustentable. Para cumplir esta obligación, los Estados deben adoptar medidas que permitan identificar tal riesgo, por ejemplo a través de un EIA o del monitoreo del proyecto correspondiente ${ }^{37}$. Quienes han comentado la sentencia de la CIJ, en el caso conocido popularmente como de las papeleras, coinciden en señalar que su aspecto más destacable dice relación con la primera de estas medidas ${ }^{38}$. Tanto Argentina como Uruguay concordaban en la necesidad de realizar un EIA para ambas papeleras, pero no estaban de acuerdo respecto al contenido y alcance de dicha evaluación ${ }^{39}$. En su fallo, la CIJ señala que se debe efectuar un EIA cuando exista el riesgo que una actividad industrial tenga un impacto transfronterizo, adverso y significativo. Agrega el tribunal que en el caso de un recurso compartido, como el río Uruguay, esta medida sería particularmente necesaria. Al no poder identificar la obligación de realizar un EIA en un artículo específico del Estatuto de 1975, la CIJ opta por interpretar el deber de proteger y preservar el medio acuático contenido en una de sus disposiciones, desde el Derecho Internacional general ${ }^{40}$. Es así como concluye que los EIA son una práctica que ha ganado tal aceptación entre los Estados, que bien puede ser considerada como una exigencia jurídica vinculada al ejercicio del deber de debida diligencia que tienen aquellos respecto de su territorio, el cual conlleva una obligación de vigilancia y de prevención ${ }^{41}$.

35 Sobre el principio de precaución y su naturaleza jurídica en el derecho internacional ambiental, ver en general id. pp. 136-7 y 152-64; y KazHDAN (2011) pp. 528-31. En relación a la aplicación de este principio por los tribunales internacionales, ver en general KazHDAN (2011). Ver, también, Boyle (2007) pp. 373-6.

36 Ver TLADi (2012) p. 10. En cuanto al principio onus probandi incumbit actori, ver plantas de celulosa sobre el río Uruguay (2010): CIJ (sentencia) párrafos 162-3.

37 Sea que esté o no en ejecución, respectivamente. Ver Birnie, Boyle y Redgwell (2009) pp. 143 y 162-4. Respecto al EIA en el derecho internacional ambiental, ver en general Birnie, Boyle y Redgwell (2009) pp. 164-75. El objetivo de esta evaluación es entregar al órgano estatal correspondiente la información necesaria relativa a los efectos ambientales de un proyecto, para su aprobación o rechazo por dicho órgano. BirNiE, Boyle y RedGWell (2009) pp. 164-6.

38 Ver Anton (2010) pp. 219-21; Merkouris (2010) pp. 2, 9 \& 11; Payne (2010a) pp. 317 y 321-3; Payne (2010b) pp. 1-2 y 5-6; Anglés Hernández (2011) p. 93; Boyle (2011) pp. 227-8; Juste Ruiz y Bou Franch (2011) pp. 23-4 y 29; Payne (2011) pp. 98-101; y Tladi (2012) pp. 8-9 y 13-4. Ver, también, los comentarios de Alan Boyle a la sentencia del asunto de las plantas de celulosa sobre el río Uruguay, efectuadas en el seminario sobre disputas ambientales organizado por el Instituto Británico de Derecho Internacional y Comparado el 26 de octubre de 2010. Disponible en: <http://www.biicl.org/files/5167_pulp_mills_case.pdf> [fecha de consulta: 1 de octubre de 2012]

39 Ver plantas de celulosa sobre el río Uruguay (2010): CIJ (sentencia) párrafo 203.

40 La CIJ hace referencia al artículo 41 del estatuto.

41 Ver plantas de celulosa sobre el río Uruguay Párrafo 204. 
Esta es la primera vez que la CIJ reconoce los EIA transfronterizos como una obligación internacional ${ }^{42}$. Sin embargo, el tribunal indica a continuación que ni el Estatuto de 1975 ni el Derecho Internacional general especifican el contenido y alcance de estos estudios $^{43}$. En su análisis, la CIJ se apoya en las "Metas y principios del estudio de impacto ambiental" adoptados en 1987 por el Programa de Naciones Unidas para el Ambiente, señalando que es una guía u orientación ofrecida por un órgano internacional de carácter técnico que, como tal, debe ser tenida en cuenta por las partes del Estatuto de 1975 al adoptar medidas regulatorias internas ${ }^{44}$. Estas "Metas y principios" requieren que un EIA contenga, al menos, una descripción de alternativas posibles y adecuadas ${ }^{45}$. Para el caso de un río compartido, la CIJ agrega que el EIA debe tener en consideración la capacidad de sus aguas para recibir, diluir y dispersar las descargas o efluentes de plantas del tipo y escala de la industria proyectada ${ }^{46}$. Todo esto lleva al tribunal a concluir que depende de cada Estado determinar -conforme a su derecho nacional- el contenido específico requerido por un EIA, teniendo presente la naturaleza y la magnitud del proyecto propuesto, y la probabilidad de impacto adverso en el medio ambiente. Según la CIJ, los EIA deben ser efectuados con anterioridad a la implementación del proyecto correspondiente. Una vez que este comience sus operaciones, sus efectos ambientales deberán ser monitoreados de manera continua ${ }^{47}$. En este contexto, llama la atención que el tribunal no reconozca una obligación de consulta a las poblaciones potencialmente afectadas como parte del Derecho Internacional, siendo que en doctrina se vincula este procedimiento al EIA ${ }^{48}$.

\section{CONCLUSIÓN}

Son pocos los casos de la CIJ que han contribuido al desarrollo del Derecho Internacional ambiental ${ }^{49}$. El asunto de las plantas de celulosa en el río Uruguay es uno de ellos probablemente el más importante, desde Gabčikovo-Nagymaros-. Esto explica que el Tribunal Internacional del Derecho del Mar (“TIDM”) lo citara al año siguiente en una opinión

\footnotetext{
42 Anton (2010) p. 219 y Boyle (2011) p. 227. No existe un deber equivalente en el derecho internacional para proyectos con efectos ambientales exclusivamente internos o de carácter global. Birnie, Boyle y Redgwell (2009) pp. 166-7.

43 Ver plantas de celulosa sobre el río Uruguay (2010): CIJ (sentencia) párrafo 205.

44 Ver plantas de celulosa sobre el río Uruguay (2010): CIJ (sentencia). Además de las "Metas y principios", Argentina invocó el "Convenio sobre estudio de impacto ambiental en un contexto transfronterizo" de 1991, mejor conocido como Convenio de Espoo, pero la CIJ no lo aplicó debido a que ninguno de los litigantes es parte de este acuerdo internacional. El Convenio de Espoo está vigente desde 1997, principalmente entre Estados europeos.

45 Ver plantas de celulosa sobre el rio Uruguay (2010): CIJ (sentencia). Párrafo 210.

46 Ver plantas de celulosa sobre el río Uruguay (2010): CIJ (sentencia). Párrafo 211.

47 Ver plantas de celulosa sobre el río Uruguay (2010): CIJ (sentencia).Párrafo 205.

48 Ver plantas de celulosa sobre el río Uruguay (2010): CIJ (sentencia). Párrafo 216.

A pesar de no poder identificar dicho deber en los instrumentos jurídicos invocados por Argentina, la CIJ concluyó que Uruguay realizó tales consultas, en ambas orillas del río. Ver plantas de celulosa sobre el río Uruguay (2010): CIJ (sentencia). Párrafos 217-9. Ver, también, Birnie, Boyle y Redgwell (2009) pp. 174-5; Anton (2010) p. 221; Payne (2010a) pp. 322-3; Payne (2010b) pp. 5-6; y Payne (2011) p. 100.

49 Ver Boyle (2011) p. 371 y Birnie, Boyle y Redgwell (2009) pp. 138-40.
} 
consultiva, corroborando que el Derecho Internacional general contempla los EIA transfronterizos ${ }^{50}$. Se le puede criticar a la CIJ cierta timidez en su contribución, como lo hace Antonio Cançado Trindade en su opinión separada ${ }^{51}$. No obstante, se debe recordar que este es un tribunal con jurisdicción de base voluntaria, por lo que depende de los estados que conforman la sociedad internacional no solo para el cumplimiento de sus decisiones judiciales, sino para seguir desempeñando su principal función: solucionar controversias internacionales. Planteamientos muy progresivos podrían disuadir a potenciales litigantes, y eso es algo que la CIJ quiere evitar, en la medida de lo posible. Desde este punto de vista, que la sentencia del asunto de las plantas de celulosa refrende la difícilmente definible noción de desarrollo sustentable, e interprete y aplique principios como la prevención, precaución y la exigencia de un EIA en proyectos de inversión con potenciales efectos para dos o más Estados, le asegura a este caso un lugar destacado en la jurisprudencia internacional ambiental. El hecho que tanto Argentina como Uruguay se hayan apoyado en estos principios al momento de presentar y fundamentar sus respectivas posiciones, confirma el rol central que tienen actualmente en el Derecho Internacional. En este sentido, el fallo de la CIJ reconoce estándares de conducta que podrán exigirse en lo sucesivo respecto de cualquier Estado que quiera implementar proyectos que puedan tener un impacto transfronterizo relevante en el medioambiente.

\section{BIBLIOGRAFÍA}

Anglés Hernández, Marisol (2011): "Fallo de la Corte Internacional de Justicia en materia ambiental, evidenciado en el asunto de plantas de celulosa sobre el río Uruguay", Anuario Mexicano de Derecho Internacional Vol. 11: pp. 77-98.

Anton, Donald (2010): "Case Concerning Pulp Mills on the River Uruguay (Argentina v. Uruguay) (Judgment) [2010] ICJ Rep (20 April 2010)", Australian International Law Journal No 17: pp. 213-23.

Birnie, Patricia; Boyle, Alan; y Redgwell, Catherine (2009): International Law and the Environment (Nueva York, EE.UU., Oxford University Press) 851 pp.

Boyle, Alan (2011): "Developments in the International Law of Environmental Impact Assessments and their Relation to the Espoo Convention", Review of European Community \& International Environmental Law, Vol. 20 No 3: pp. 227-31.

Boyle, Alan (2007): "The Environmental Jurisprudence of the International Tribunal for the Law of the Sea”, The International Journal of Marine and Coastal Law, Vol. 22 No 3: pp. 369-81.

\footnotetext{
50 Kazhdan (2011) p. 547. Ver responsabilidades y obligaciones de los Estados que patrocinan personas y entidades respecto de actividades en la zona (2011): TIDM (opinión consultiva) párrafos 147-8. La sentencia de la CIJ en el asunto de las plantas de celulosa en el río Uruguay es, a la fecha, el precedente internacional más importante en materia de EIA. Boyle (2011) p. 227.

51 Según este juez, la sentencia no identifica con claridad la prevención, precaución y desarrollo sustentable como principios generales del derecho internacional ambiental. Ver, en general, plantas de celulosa sobre el río Uruguay (2010): CIJ (opinión separada del juez Trindade) párrafos 52-147.
} 
Juste Ruiz, José, y bou franch, Valentín (2011): "El caso de las plantas de celulosa sobre el río Uruguay: Sentencia de la Corte Internacional de Justicia de 20 de abril 2010”, Revista Electrónica de Estudios Internacionales, No 21: pp. 1-31. Disponible en:

$<$ http://www.reei.org/index.php/revista/num21/articulos/caso-plantas-celulosa-sobre-riouruguay-sentencia-corte-internacional-justicia-20-abril-2010> [fecha de consulta: 1 de octubre de 2012]

Kazhdan, Daniel (2011): "Precautionary Pulp: Pulp Mills and the Evolving Dispute between International Tribunals over the Reach of the Precautionary Principle", Ecology Law Quarterly, Vol. 38 No 2: pp. 527-52.

Merkouris, Panos (2010): "Case Concerning Pulp Mills on the River Uruguay (Argentina v. Uruguay): Of Environmental Impact Assessments and 'Phantom Experts”, The Hague Justice Portal. Disponible en:

<http://www.haguejusticeportal.net/index.php?id=11878> [fecha de consulta: 1 de octubre de 2012].

Pavón Piscitello, Daniel, y Andrés, Gabriel Eugenio (2007): “The Conflict between Argentina and Uruguay Concerning the Installation and Commissioning of Pulp Mills before the International Court of Justice and MERCOSUR", Heidelberg Journal of International Law, Vol. 67: pp. 159-83.

Payne, Cymie (2010): "Environmental Impact Assessments as a Duty under International Environmental Law: The ICJ Judgment on Pulp Mills on the River Uruguay", European Journal of Risk Regulation, Vol. 3: pp. 317-24.

Payne, Cymie (2011): "Pulp Mills on the River Uruguay (Argentina $v$. Uruguay). At http://icj-cij.org. International Court of Justice, April 20, 2010", American Journal of International Law, Vol. 105 No 1: pp. 94-101.

Payne, Cymie (2010): "Pulp Mills on the River Uruguay: The International Court of Justice Recognizes Environmental Impact Assessment as a Duty under International Law”, American Society of International Law Insights, Vol. 14 No 9. Disponible en:

<http://www.asil.org/insights100422.cfm> [fecha de consulta: 1 de octubre de 2012].

Tladi, Dire (2012), "Principles of Sustainable Development in the Case Concerning Pulp Mills on the River Uruguay", International Development Law Organization Legal Working Paper. Disponible en:

$<$ http://www.idlo.int/Documents/Rio/01.\%20Pulp\%20Mills\%20on\%20the\%20River\%20 Uruguay.pdf> [fecha de consulta: 1 de octubre de 2012].

\section{JURISPRUDENCIA CITADA}

Asunto del estrecho de Corfú, Reino Unido c. Albania (1949): Corte Internacional de Justicia, 9 de abril de 1949 (sentencia). Disponible en francés e inglés en http://www.icj-cij.org/ docket/files/1/1645.pdf [fecha de consulta: 1 de octubre de 2012]

Asunto relativo a las plantas de celulosa sobre el río Uruguay, Argentina c. Uruguay (2006): Corte Internacional de Justicia, 13 de julio de 2006 (medidas provisionales). Disponible en francés e inglés en http://www.icj-cij.org/docket/files/135/11235.pdf [fecha de consulta: 1 de octubre de 2012] 
Asunto relativo a las plantas de celulosa sobre el río Uruguay, Argentina c. Uruguay (2007): Corte Internacional de Justicia, 23 de enero de 2007 (medidas provisionales). Disponible en francés e inglés en http://www.icj-cij.org/docket/files/135/13615.pdf [fecha de consulta: 1 de octubre de 2012]

Asunto relativo a las plantas de celulosa sobre el rio Uruguay, Argentina c. Uruguay (2010): Corte Internacional de Justicia, 20 de abril de 2010 (sentencia). Disponible en francés e inglés en http://www.icj-cij.org/docket/files/135/15877.pdf [fecha de consulta: 1 de octubre de 2012]

Asunto relativo a las plantas de celulosa sobre el río Uruguay, Argentina c. Uruguay (2010): Corte Internacional de Justicia, 20 de abril de 2010 (opinión separada del juez Antonio Cançado Trindade). Disponible en francés e inglés en http://www.icj-cij.org/docket/ files/135/15885.pdf [fecha de consulta: 1 de octubre de 2012]

Asunto relativo al proyecto Gabčikovo-Nagymaros, Hungría c. Eslovaquia (1997): Corte Internacional de Justicia, 25 de septiembre de 1997 (sentencia). Disponible en francés e inglés en http://www.icj-cij.org/docket/files/92/7375.pdf [fecha de consulta: 1 de octubre de 2012]

Legalidad de la amenaza o el uso de armas nucleares por un estado en un conflicto armado (1996): Corte Internacional de Justicia, 8 de julio de 1996 (opinión consultiva). Disponible en francés e inglés en http://www.icj-cij.org/docket/files/93/7407.pdf [fecha de consulta: 1 de octubre de 2012]

Responsabilidades y obligaciones de los Estados que patrocinan personas y entidades respecto de actividades en la zona (2011): Tribunal Internacional de Derecho del Mar, 1 de febrero de 2011 (opinión consultiva). Disponible en inglés en https://www.itlos.org/fileadmin/ itlos/documents/cases/case_no_17/adv_op_010211.pdf [fecha de consulta: 1 de octubre de 2012]. 